\title{
Refractory Anaplastic Pleomorphic Xanthoastrocytoma
}

National Cancer Institute

\section{Source}

National Cancer Institute. Refractory Anaplastic Pleomorphic Xanthoastrocytoma. NCI

Thesaurus. Code C160905.

Anaplastic pleomorphic xanthoastrocytoma that is resistant to treatment. 